\title{
O DIREITO À CIDADE: EFICIÊNCIA DA POLÍTICA NACIONAL DE RESÍDUOS SÓLIDOS À LUZ DA ANÁLISE ECONÔMICA DO DIREITO
}

\section{THE RIGHT TO THE CITY: EFFICIENCY OF THE NATIONAL SOLID WASTE POLICY IN THE PERSPECTIVE OF ECONOMIC ANALYSIS OF LAW}

\author{
Eloi Rodrigues Barreto Pethechust ${ }^{1}$ \\ Ligia Maria Silva Melo de Casimiro ${ }^{2}$
}

\section{Resumo}

O desenvolvimento socioambiental que garante o acesso ao direito à cidade tem sido ameaçado por problemas relacionados aos resíduos sólidos. Com o crescimento acelerado e desconectado de planejamento urbano, ano após ano, o volume de lixo produzido tem provocado degradação, colocado em risco a sustentabilidade, impedindo que a função social da cidade se materialize. A Lei $n^{\circ}$. 12.305/2010, que institui a Política Nacional de Resíduos Sólidos, representa um avanço no tocante ao incentivo a comportamentos ambientalmente corretos com o tratamento do lixo no cenário urbano. No entanto, os instrumentos de incentivo são em boa parte direcionados a empresas e ao Poder Público, não contemplando de maneira suficiente o cidadão, apontado como um dos principais agentes geradores dos resíduos sólidos domésticos no âmbito das cidades. Nesse contexto, a presente investigação cientifica, à luz da análise econômica do Direito, propõe reflexão sobre alguns instrumentos de incentivo a diminuição de geração, a reutilização, reaproveitamento e reciclagem do lixo voltados a figura do cidadão consumidor, sujeito imerso em uma ética de descarte e sem estímulos à mudança de comportamento. Para tanto, foi empregado o método dedutivo de investigação científica, utilizando como base a revisão bibliográfica relativa às questões expostas no presente artigo.

Palavras chave: Desenvolvimento. Direito à cidade. Resíduos sólidos urbanos. Análise econômica do Direito. Consumidor.

\begin{abstract}
The social and environmental development that ensures access to the right to the city has been threatened by problems related to solid waste. With the rapid growth and disconnected from urban planning, year after year, the volume of waste produced has caused degradation, put at risk the sustainability, preventing the social function of the city materializes. The Law no. 12,305 / 2010, which established the National Policy on Solid Waste, represents a breakthrough in regard to encouraging environmentally friendly behavior with waste treatment in urban setting. However, the incentive tools are largely aimed at businesses and the government, not contemplating sufficiently citizen, named as one of the main generating agents of the domestic solid waste within cities. In this context, the present scientific research in light of the economic analysis of law, proposes reflection on some instruments to encourage the reduction of generation, reuse, reuse and recycling of waste aimed at the consumer citizen figure, subject immersed in a discard ethics

1 Bolsista da CAPES/PROSUP. Doutorando em Direito Econômico e Socioambiental pela Pontifícia Universidade Católica do Paraná. E-mail: pethechust@hotmail.com

2 Doutoranda em Direito Econômico e Socioambiental pelo Dinter PUC/PR/URCA/CE. Professora dos cursos de graduação e pós-graduação da FAP, Juazeiro do Norte, CE, da URCA/Crato, CE e do curso de pósgraduação do Instituto Romeu Felipe Bacellar, em Curitiba, PR. Presidente do Instituto Cearense de Direito Administrativo. Diretora do Instituto Brasileiro de Direito Urbanístico. Advogada. E-mail: meloligia@gmail.com
\end{abstract}


and no incentives to change behavior. For this, we used the deductive method of scientific research, using as a basis a literature review relating to matters set out in this article.

Keywords: Development. Right to the City. Urban solid waste. Economic Analysis of Law. Consumer 


\section{INTRODUÇÃO}

O desenvolvimento socioambiental é um dos temas mais discutidos nos últimos tempos. Dentre as várias questões que o englobam, no Brasil, talvez uma das mais candentes e debatidas reside no lixo urbano, denominado juridicamente como resíduos sólidos e rejeitos.

No âmbito das cidades brasileiras, os resíduos sólidos urbanos, com ênfase para os resíduos domésticos, representam um dos principais desafios ao desenvolvimento social e ambiental que garanta o acesso ao direito à cidade.

Nesse contexto, a presente pesquisa se propõe a investigar a eficiência da Lei $n^{\circ}$. 12.305/2010, que institui a Política Nacional de Resíduos Sólidos e complementa o rol de legislações que protegem o direito à cidade, no tocante a degradação socioambiental urbana causada pela geração desregrada de resíduos sólidos domésticos.

Para tanto, irá se analisar a eficiência dos instrumentos de incentivo econômico estabelecidos pela Lei voltados a gestão responsável dos resíduos sólidos urbanos, com enfoque na figura do cidadão consumidor, o principal agente produtor dos resíduos sólidos domésticos, a partir do conceito de cidade e sua função social, da ideia de desenvolvimento socioambiental nas cidades e como os resíduos sólidos representem um empecilho a esse desenvolvimento. $\mathrm{Na}$ sequência, faz-se uma breve análise de tais mecanismos à luz da Análise Econômica do Direito, verificando a eficiência da Lei no tocante à degradação ambiental nas cidades causada pelos resíduos sólidos domésticos.

\section{O DIREITO À CIDADE E O DESENVOLVIMENTO SOCIOAMBIENTAL DAS CIDADES: RESÍDUOS SÓLIDOS DOMÉSTICOS E OS MECANISMOS INDUTORES DE PRÁTICAS RESPONSÁVEIS}

A cidade é o espaço em que se materializam as relações humanas. É um organismo vivo, resultado de fatores históricos, econômicos, culturais, onde as pessoas se reúnem em torno de um valor que Ihes proporcione melhoria de vida. ${ }^{3}$

Sendo assim, o direito à cidade surge como um termo utilizado por urbanistas, filósofos, sociólogos e juristas, que identificam e reconhecem a presença do cidadão urbano como construtor e destinatário de um espaço que reproduz as características das relações

\footnotetext{
3 LUFT, Rosângela Marina. Políticas Públicas Urbanas: premissas e condições para a efetivação do direito à cidade. Belo Horizonte: Fórum, 2011, p.113.
} 
socioeconômicas e jurídicas. A cidade se confunde com o próprio sistema econômico capitalista, de matiz industrial, no qual o ser humano é idealizador, protagonista e usufruidor. Em seu território convivem todas as necessidades e desigualdades socioeconômicas. A presença humana, o ser e o estar na cidade são, então, resultando de uma constante busca humana consagrada como um direito. $^{4}$

Diante dos anseios e necessidades humanas a cidade é o resultado de um processo socioeconômico e cultural, em um contexto da industrialização que tem gerado uma urbanização extensa e adensada, que maltrata o meio ambiente natural de maneira progressiva. ${ }^{5}$

Compreendida como um sistema de elementos com a finalidade de garantir subsistência e proteção ao ser humano, representa uma associação de pessoas que se relacionam em função de seus interesses e necessidades na busca por viver bem, ainda que o façam com certa dificuldade. ${ }^{6}$

Sobre compreender e identificar a cidade, Max Weber a analisa destacando sua funcionalidade econômica. ${ }^{7}$ Em 1933 um conceito mais específico foi vinculado à cidade, expresso na Carta de Atenas, indicando a noção da funcionalidade do território urbano, em que as pessoas deveriam ter, minimamente, a possibilidade de habitar, trabalhar, se divertir e circular. ${ }^{8} \mathrm{O}$ documento expedido auxiliou no debate científico e prático da construção do espaço urbano, ainda que insuficiente.

Em fins do século XX, mais precisamente em 1998, uma nova Carta foi apresentada à comunidade internacional, prospectando, em especial, as cidades europeias para o século XXI. Defende-se que sua funcionalidade seria efetiva se considerassem as cidades de maneira interligada, em rede, envolvendo suas necessidades e serviços. Em 2003, um novo debate foi feito

4 HEIDEGGER, Martin. Construir, Habitar, Pensar, trad. de Marcia Sá Cavalcante Schuback in: http://www.prourb.fau.ufrj.br/jkos/p2/heidegger_construir,\%20habitar,\%20pensar.pdf, p.1. Acesso em 20 de fevereiro de 2015.

${ }^{5}$ LEFEBVRE, Henri. O Direito à Cidade. Tradução de Rubens Frias. Primeira Edição, Editora Moraes, São Paulo. 1991, p. 10.

${ }^{6}$ A cidade reúne pessoas que necessitam estar em sociedade, agregando-se e humanizando-se, convivendo umas com as outras na busca segura pela tentativa da realização de seus anseios. ELIAS, Norbert. A Sociedade dos indivíduos. SCHROTER, Michael (org.); RIBEIRO, Vera (trad.); Rio de Janeiro: Jorge Zahar, 1994. p.72-75.

${ }^{7}$ WEBER, M. La ciudad. Madri: La Piqueta, 1987. p. 4.

${ }^{8}$ A ideia de cidade funcional, para definir qual o papel do centro urbano na vida de um cidadão, foi listado formalmente, a partir das ideias de Le Corbusier, durante o IV Congresso Internacional de Arquitetura Moderna em 1933, em Atenas seguintes funções urbanas elementares: habitação, trabalho, recreação e circulação no espaço urbano. SILVA, José Afonso da. Direito Urbanístico Brasileiro. São Paulo: Malheiros, 2006. p. 29-30. 
na Comunidade Européia e a concepção técnica de cidade passou a agregar o valor da coerência, unindo-se aos ideais de funcionalidade e atuação "em rede". 9

A nova Carta, então, propõe uma visão das cidades em rede, indicando que as mesmas devam estar voltadas para "conservar a riqueza cultural e diversidade, construída ao longo da história; conectar-se através de uma variedade de redes funcionais; manter uma fecunda competitividade, porém esforçando-se para a colaboração e cooperação e contribuir para o bemestar de seus habitantes e usuários". ${ }^{10}$

Ainda que tal prospecção seja mais próxima da realidade europeia, no Brasil as necessidades dos cidadãos, e o sistema jurídico, também indicam a mesma configuração de cidade.

A cidade coerente pode ser compreendida no formato da urbes sustentável que se pretende desenvolvida e acessível a todos, coerente com a previsão de direitos fundamentais do ser humano, direcionando para um desdobramento do alcance material e uso racional dos recursos naturais. ${ }^{11}$

No entanto, parte das cidades, tanto em nível nacional como internacional, não atende aos anseios de uso racional dos recursos naturais. De forma sistemática observa-se uma baixa qualidade ambiental da vida nas cidades, a qual é marcada por questões como:

1. Diversidade de poluição resultante de atividades industriais;

2. Sistema de transporte marcado pela presença maciça de automóveis;

3. Distribuição desigual de equipamentos urbanos e comunitários,

4. Definição de padrões de uso e ocupação do solo urbano inadequados à infraestrutura existente;

5. Ausência de áreas verdes;

6. Qualidade técnica das construções dissociadas de instrumental preservacionista e sustentável; e

7. Descomunal geração e inadequada destinação de resíduos sólidos. ${ }^{12}$

\footnotetext{
${ }^{9}$ MARRARA, Thiago. Bens Públicos: Domínio Urbano: Infra-estruturas. Belo Horizonte: Fórum, 2007, p. 248.

10 LA NOUVELLE CHARTE d'ATHÈNES 2003, disponível em www.ceu-ectp.org. Acessado em 20/02/2015.

11 KANASHIRO, Milena. Da antiga à nova Carta de Atenas - em busca de um paradigma espacial de sustentabilidade. Desenvolvimento e Meio ambiente, n. 9, p. 33-37, jan. /jun. Curitiba: Editora UFPR, 2004, p. 36-37.

12 KAHN, Suzana. Reflexões sobre sustentabilidade urbana. Cienc. Cult., São Paulo, v. 67, n. 1, março 2015. Disponível a partir de < http://cienciaecultura.bvs.br/scielo.php?script=sci_arttext\&pid=S000967252015000100002\&lng=en>. Acesso em 15 de abril de 2015, p.4.
} 
Diante de tal realidade, observar a regulamentação sobre os resíduos sólidos urbanos é um dos pontos relevantes no tocante a degradação ambiental das cidades. O lixo gerado pelas cidades, mais especificamente os Resíduos Sólidos Doméstico - RDO, certamente é um dos grandes gargalos contrapostos ao ideal de cidade funcional sustentável, comprometendo a qualidade de vida do cidadão e o desenvolvimento socioambiental.

Nesse sentido, Maurício de Souza Bernardes ressalta que "dentro da perspectiva da degradação ambiental das cidades, um dos pontos mais relevantes tem sido a geração de resíduos sólidos urbanos, e, mais especificamente, os Resíduos Sólidos Domésticos". ${ }^{13}$

Os RDO gerado pelas cidades tem sido um dos principais problemas não apenas a nível local, mas também nacional e internacional, no que se refere ao problema do lixo. Segundo algumas pesquisas, no mundo são descartados cerca de 2 milhões de toneladas de resíduos domiciliares diariamente, o que gera por ano a vultuosa quantia de 730 milhões de toneladas. Ainda, se os resíduos domésticos foram somados a outros refugos provenientes das atividades humanas nas cidades, temos a somatória de 30 bilhões de toneladas de lixo por ano. Se estima que nesse ritmo frenético de geração de rejeitos chegaremos a 1,5 trilhão de toneladas de lixo no ano $2.050 . .^{14}$

No Brasil os números também são alarmantes. Segundo o relatório Resíduos Sólidos no Brasil, elaborado pala Associação Brasileira de Limpeza Pública e Resíduos Especiais, anualmente a produção de resíduos sólidos tem ultrapassado a taxa de crescimento populacional. Por exemplo, comparando os relatórios de 2012 e 2013, verifica-se que houve um aumento de 4,1\% na taxa de geração de Resíduos Sólidos Urbanos no Brasil em 2013, sendo que a taxa de crescimento populacional no país nesse período foi de $3,7 \% .{ }^{15}$ Ou seja, a cada ano o crescimento da quantidade de lixo produzido é superior ao crescimento da própria população nas cidades.

Os resíduos gerados de forma desenfreada e sem adequada destinação no ambiente urbano acabam prejudicando e comprometendo o desenvolvimento socioambiental das cidades, criando um cenário que aflige pesquisadores, gestores públicos e a população como um todo.

\footnotetext{
${ }^{13}$ BERNARDES, Maurício de Souza. Os desafios para efetivação da Política Nacional de Resíduos Sólidos frente a figura do consumidor-gerador. Revista Eletrônica do Curso de Direito da UFSM. v. 8, p. 196-207, 2013. p. 199

${ }^{14}$ WALDMAN, Maurício. Lixo: cenários e desafios - abordagens básicas para entender os resíduos sólidos. São Paulo: Cortez, 2010. p. 45

15 PANORAMA DOS RESÍDUOS SÓLIDOS NO BRASIL 2013 - Abrelpe. Disponível em: <http://www.abrelpe.org.br/Panorama/panorama2013.pdf>. Acessado em 23 set. 2015
} 
No tocante a questão do lixo, a busca pela minimização desse descompasso entre o projeto de cidade sustentável e a produção de resíduos no ambiente urbano pode ser encontrada na Lei n. 12.305/2010, que institui a Política Nacional de Resíduos Sólidos.

A Lei em questão trouxe vários mecanismos jurídicos que visam minimizar a degradação ambiental causada pelo lixo. Dentre eles, podemos citar:

1. Responsabilidade compartilhada pelo ciclo da vida dos produtos, estimulando a cooperação entre diversos envolvidos na produção dos resíduos;

2. Determinação aos municípios, microrregiões e regiões metropolitanas a instituição de um plano de resíduos sólidos;

3. Cria o Sistema Nacional de Informações sobre a Gestão de Resíduos Sólidos;

4. Estabelecimento do princípio do poluidor-pagador, impondo uma série de sanções aplicáveis àqueles que destinarem de forma inadequada os resíduos;

5. Criação do princípio do protetor-recebedor, através de instrumentos que conferem benefícios econômicos (incentivos fiscais, financeiros ou creditícios) aos sujeitos que adotem mecanismos de prevenção, precaução, redução da geração de resíduos e tecnologias que visem o desenvolvimento e consumo sustentável; dentre outros.

Dentre esses diversos mecanismos, observam-se as medidas indutoras adotadas pela Lei da Política Nacional de Resíduos Sólidos sob o enfoque da Análise Econômica do Direito, com o objetivo de investigar se a Lei em questão é eficiente no enfrentamento do problema dos resíduos sólidos domésticos, um dos agentes de degradação e prejuízo do desenvolvimento socioambiental das cidades.

\section{ANÁLISE ECONÔMICA DA POLÍTICA NACIONAL DE RESÍDUOS SÓLIDOS: INCENTIVOS E INIBIÇÕES AO ADEQUADO TRATAMENTO DOS RESÍDUOS SÓLIDOS DOMÉSTICOS}

O ser humano, em regra, pauta seu comportamento e toma decisões buscando a maximização de seu próprio bem-estar. Nesta busca, os indivíduos constantemente realizam escolhas efetivadas de acordo com o que elegem para si como mais útil. Assim, toda vez que uma pessoa toma uma decisão, entre duas ou mais opções, sempre prefere a que the traga mais utilidade, ou seja, sempre escolhe a opção que the proporcione o maior bem-, dentro do que particularmente considera como bem-estar. É a racionalidade econômica do ser humano. 
Assim, pode-se dizer que as pessoas constantemente avaliam os custos e benefícios das opções disponíveis e, através da ponderação individual, adotam a opção mais vantajosa. ${ }^{16} \mathrm{~A}$ racionalidade econômica leva os indivíduos a fazer suas escolhas a partir da melhor situação que idealizam para si próprios. Cabe ressaltar que a teoria da racionalidade econômica não pressupõe que cada agente esteja o tempo todo conscientemente efetuando cálculos e ponderando vantagens e prejuízos de cada ato de sua vida, mas considera que na média as pessoas se comportam como se assim estivessem. ${ }^{17}$

Nesse contexto, a análise econômica constitui um instrumental analítico e empírico da economia, utilizado para tentar compreender, explicar e prever as decisões dos agentes em um ambiente que envolva escolhas. Lionel Robbins define a análise econômica como "a ciência que estuda o comportamento humano como uma relação entre fins e meios escassos que possuem usos alternativos". ${ }^{18}$

Já a Análise Econômica do Direito - AED - é um método de investigação cujo objetivo é analisar as implicações fáticas do ordenamento jurídico sobre o comportamento dos agentes. Partindo do pressuposto de que as pessoas tomam decisões e pautam suas ações avaliando custos e benefícios, a lei, ao criar um benefício ou um custo para determinado comportamento, pode incentivar uma alteração na conduta das pessoas.

Em um dos primeiros estudos no Brasil, a respeito do estreito universo das relações jurídicas atreladas aos conceitos e modo de raciocínio próprios das ciências econômicas, Estrella Faria exemplifica a questão através da relação custo/benefício do crime, em que as vantagens do ato delituoso superam os custos esperados. ${ }^{19}$ Assim, ainda que determinado delito conte com uma pena alta, se a incidência de pessoas presas for baixa, o criminoso, ponderando os benefícios esperados com o delito e as chances mínimas de ser preso, optará pela ação delituosa.

${ }^{16}$ GONÇALVES, Oksandro Osdival; TOSI, Caroline Hammerschmidt Amaro. Teoria econômica do namoro e do matrimônio: uma ponderação sobre os custos e vantagens que determinam a decisão dos indivíduos. In: VI Congresso da Associação Brasileira de Direito e Economia - ABDE, 2013, Rio de Janeiro. Disponível em: < http://www.congresso.abde.com.br/index.php/ABDE/VI_ABDE/paper/view/183/5>. Acesso em 29 de jul. 2014, p. 5-6

${ }^{17}$ GICO Jr., Ivo Teixeira. Metodologia e Epistemologia da Análise Econômica do Direito. Economic Analysis of Law Review, v. 1, p. 7-32, jan./jun. 2010, p. 26

${ }^{18}$ Segundo Robbins "Economics is the science which studies human behaviour as a relationship between ends and scarce means which havealternative uses." ROBBINS, Lionel. An Essay on the Nature and Significance of Economic Science. London: Macmillan, 1932, p. 15. Disponível em: <http://library.mises.org/books/Lionel\%20Robbins/Essay\%20on\%20the\%20Nature\%20and\%20Significance\% 20of\%20Economic\%20Science.pdf>. Acesso em 29 de jul. 2014

19 FARIA, Guiomar Theresinha Estrella. Interpretação econômica do Direito. Porto Alegre: Livraria do Advogado, 1994, p. 34-35. 
Deste modo, a AED permite realizar determinadas previsões comportamentais, com base nos custos e benefícios criados pelo ordenamento jurídico. Nesse sentido elucida Ivo T. Gico Junior:

Os juseconomistas têm como principal característica considerar o direito enquanto um conjunto de regras que estabelecem custos e benefícios para os agentes que pautam seus comportamentos em função de tais incentivos. Assim, a abordagem juseconômica investiga as causas e as consequências das regras jurídicas e de suas organizações na tentativa de prever como cidadãos e agentes públicos se comportarão diante de uma dada regra e como alterarão seu comportamento caso essa regra seja alterada. ${ }^{20}$

A AED, portanto, é uma ferramenta de investigação cientifica que possibilita a previsibilidade do comportamento humano diante do conjunto de regras postas no ordenamento jurídico.

Analisando a Lei $n^{\circ}$. 12.305/2010 sob a ótica da AED, observa-se que foram previstos diversos mecanismos indutores voltados a adequação do comportamento dos agentes econômicos às práticas ambientalmente responsáveis com o ciclo da vida dos produtos.

A Lei designa no art. 42 que o poder público poderá instituir medidas indutoras e linhas de financiamento para atender às iniciativas de:

1. "Prevenção e redução da geração de resíduos sólidos no processo produtivo";

2. "Desenvolvimento de produtos com menores impactos à saúde humana e à qualidade ambiental em seu ciclo de vida";

3. "Implantação de infraestrutura física e aquisição de equipamentos para cooperativas ou outras formas de associação de catadores de materiais reutilizáveis e recicláveis formadas por pessoas físicas de baixa renda"; dentre outras. ${ }^{21}$

Um pouco adiante, no artigo 44, caput, a Lei também prevê que a União, os Estados, o Distrito Federal e os Municípios poderão instituir incentivos fiscais, financeiros ou creditícios, respeitadas as limitações da Lei de Responsabilidade Fiscal. Na sequência, o dispositivo estabelece quais sujeitos são destinatários das medidas indutoras propostas pela Lei, sendo eles:

${ }^{20}$ GICO Jr., Ivo Teixeira. Metodologia e Epistemologia da Análise Econômica do Direito. Economic Analysis of Law Review, v. 1, p. 7-32, jan./jun. 2010, p. 20-21

${ }^{21}$ (...) III - implantação de infraestrutura física e aquisição de equipamentos para cooperativas ou outras formas de associação de catadores de materiais reutilizáveis e recicláveis formadas por pessoas físicas de baixa renda; IV - desenvolvimento de projetos de gestão dos resíduos sólidos de caráter intermunicipal ou, nos termos do inciso I do caput do art. 11 , regional; $V$ - estruturação de sistemas de coleta seletiva e de logística reversa; VI - descontaminação de áreas contaminadas, incluindo as áreas órfãs; VII desenvolvimento de pesquisas voltadas para tecnologias limpas aplicáveis aos resíduos sólidos; VIII desenvolvimento de sistemas de gestão ambiental e empresarial voltados para a melhoria dos processos produtivos e ao reaproveitamento dos resíduos." 
1. "Indústrias e entidades dedicadas à reutilização, ao tratamento e à reciclagem de resíduos sólidos produzidos no território nacional";

2. "Projetos relacionados à responsabilidade pelo ciclo de vida dos produtos, prioritariamente em parceria com cooperativas ou outras formas de associação de catadores de materiais reutilizáveis e recicláveis formadas por pessoas físicas de baixa renda"; e, por fim,

3. "Empresas dedicadas à limpeza urbana e a atividades a ela relacionadas.".

Observa-se que a Lei em debate trouxe incentivos para uma série de iniciativas voltadas às empresas e ao Poder Público, porém possui insignificante mecanismo de indução ao adequado tratamento dos resíduos sólidos pelo consumidor, o principal agente gerador de resíduos sólidos domésticos nas cidades.

O único instrumento reside no sistema de coleta seletiva. Em seu art. 35, parágrafo único, a Lei estabelece que "o poder público municipal pode instituir incentivos econômicos aos consumidores que participam do sistema de coleta seletiva referido no caput, na forma de lei municipal. ". Portanto, analisando sistematicamente, a Lei brasileira não apresenta instrumentos suficientes que atinjam o cerne do problema, que está vinculado ao consumo e ao descarte desenfreado. 22

O Papa Francisco, na Carta Encíclica Laudato Sí, que aborda diversas questões relacionadas a proteção ambiental do planeta, aponta como um dos eixos centrais de preocupação com a nossa "casa comum" a cultura do descarte. Segundo o Papa:

A terra, a nossa casa, parece transformar-se cada vez mais num imenso depósito de lixo (...) estes problemas estão relacionados à cultura do descarte (...) nota-se, por exemplo, como a maior parte do papel produzido se desperdiça sem ser reciclado.

Conclui-se que a Lei $n^{\circ}$. 12.305/2010, em que pese representar um importante avanço no tocante ao problema dos resíduos sólidos no país, pecou em não estabelecer um rol de instrumentos de incentivo voltados ao consumidor, o que prejudica e coloca em risco o desenvolvimento socioambiental nas cidades.

22 FRANCISCO, Papa. Carta Encíclica Laudato Sí. Disponível em: <http://w2.vatican.va/content/francesco/pt/encyclicals/documents/papafrancesco_20150524_enciclicalaudato-si.html>. Acessado em 22 set. 2015. p. 19-20 


\section{A CHAVE PARA O PROBLEMA DOS RESÍDUOS SÓLIDOS URBANOS: A FIGURA DO CONSUMIDOR-GERADOR}

A lógica atual de mercado repousa, em grande parte, no consumo, descarte e reposição constantes dos produtos, e o consumidor constitui-se na mola propulsora de tal economia, sendo a figura central que mantem em movimento continuo os produtos em circulação. Assim, constitui um dos principais agentes responsáveis pela geração de resíduos sólidos, principalmente os resíduos sólidos domésticos.

Portanto, em tempos de consumo, descarte e obsolescência programada, enfrentar o problema dos resíduos sólidos importa na criação de mecanismos de incentivo a um consumo ambientalmente responsável, que englobe a diminuição da sua geração, o seu reaproveitamento, reutilização e reciclagem.

Em primeiro lugar, cabe a criação de instrumentos que induzam os consumidores a mudar sua visão acerca dos resíduos sólidos, os quais devem deixar de ser encarados como "lixo", sobra e rejeito, para ser compreendidos como parte de um processo circular, no qual os resíduos devem ser reaproveitados e reutilizados, em uma chamada "economia circular". Ou seja, o lixo não deve ser mais encarado pelo consumidor como fim, mas sim como meio, passando de subproduto para produto por excelência em uma lógica ambientalmente responsável. ${ }^{23}$

Isso porque, embora os governantes e empresas possam adotar ações coletivas, por exemplo, de reciclagem, se elas não forem assimiladas pelos consumidores tenderão a ser falhas. Ainda que sejam criados nos ambientes públicos e privados recipientes apropriados para coleta seletiva do lixo, de nada servirão se as pessoas não estiverem acostumadas a utiliza-los e realizar a adequada separação dos resíduos. ${ }^{24}$ É necessário que o consumidor incorpore um modelo circular de consumo, em que seja possível absolver e reutilizar os resíduos sólidos e escórias. Vale dizer, uma parte da resolução está assentada na modificação da "cultura do descarte". ${ }^{25}$

O segundo ponto reside na redução do consumo. É imprescindível que sejam instituídas ferramentas voltadas ao estimulo do consumidor a um consumo consciente, equilibrado e sem

\footnotetext{
${ }^{23}$ WALDMAN, Maurício. Lixo: cenários e desafios - abordagens básicas para entender os resíduos sólidos. São Paulo: Cortez, 2010. p. 125

${ }^{24}$ GHELLER, Giovanna. O tripé em que se apoia a sustentabilidade. Revista Espaço Aberto USP, ed 157, fev. 2014. Disponível em: <http://www.usp.br/espacoaberto/?materia=o-tripe-em-que-se-apoia-asustentabilidade>. Acessado em 25 set. 2015.

25 FRANCISCO, Papa. Carta Encíclica Laudato Sí. Disponível em: <http://w2.vatican.va/content/francesco/pt/encyclicals/documents/papafrancesco_20150524_enciclicalaudato-si.html>. Acessado em 22 set. 2015. p. 20
} 
exageros. Pode-se pensar, por exemplo, na regulamentação do marketing desenfreado realizados pelas mídias contemporâneas que guiam os consumidores para consumirem cada vez mais, por um lado, e na criação de programas de conscientização nas mídias voltados ao estimulo da diminuição do consumo e do descarte, por outro. ${ }^{26}$

Ainda, outra medida a ser adotada reside na internalização dos custos ambientais do consumo. É necessário induzir comportamentos de redução na produção de resíduos por meio da responsabilidade que atinja também o consumidor. ${ }^{27}$ Nesse sentido, imagine-se, por exemplo, cotas de produção de lixo para os consumidores, de modo que os que produzam lixo além da sua cota pessoal tenham que pagar taxas extras ao Estado. Uma medida que a longo prazo estimularia o consumidor a procurar por produtos não descartáveis ou reaproveitáveis, estimulando, por via reflexa, o próprio mercado a se adequar ao novo padrão de consumo.

Tais instrumentos de estimulo ao consumo ambientalmente responsável não excluem outras possibilidades, constituem apenas algumas ferramentas voltadas ao enfrentamento do cerne da degradação socioambiental das cidades, na medida em que são voltadas ao consumidor, principal agente produtor dos resíduos sólidos domésticos.

\section{CONCLUSÃO}

A degradação ambiental urbana causada pelos resíduos sólidos domésticos é, na atualidade, um dos grandes desafios a ser enfrentado na busca pelo desenvolvimento socioambiental das cidades.

Em que pese a que instituiu a Política Nacional de Resíduos Sólidos ser um grande avanço no tema, com alguns mecanismos de incentivo a condutas ambientalmente responsáveis no tocante a gestão dos resíduos sólidos, denota-se que seu enfoque recai sobremaneira nas empresas e no Poder Público, destinando ao cidadão consumidor, um dos principais agentes de produção de resíduos sólidos domésticos, uma atenção pouco significativa.

Assim sendo, com o objetivo de se fazer cumprir o ideal da função social e do direito à cidade, faz-se necessário que sejam instituídos mecanismos indutores de condutas

${ }^{26}$ BERNARDES, Maurício de Souza. Os desafios para efetivação da Política Nacional de Resíduos Sólidos frente a figura do consumidor-gerador. Revista Eletrônica do Curso de Direito da UFSM. v. 8, p. 196-207, 2013. p. 205

${ }^{27}$ KALIL, Ana Paula Maciel Costa; TAVARES NETO, José Querino. Elaboração de políticas públicas com base na governança: o caso da política nacional de resíduos sólidos. In: PAULA, Gil César Costa de; SILVA, José Antônio Tietzmann e; ARAÚJO, Luciane Martins de (cood.). Sustentabilidade: desafios e perspectivas. Goiás: Gráfica e Editora América. 2015. p. 383/390 
ambientalmente responsáveis no tocante a questão do lixo, voltados ao cidadão consumidor, especificamente. Dentre os instrumentos a serem criados, propõe-se:

1. Promoção do reconhecimento do espaço urbano ambiental como uma extensão da habitação, criando uma cultura de zelo que possa protege-lo da degradação;

2. Mais utilização de mecanismos que impõe planejamento urbano ambiental;

3. A incorporação na sociedade de uma visão do lixo como meio, não como fim, do processo produtivo, substituindo a cultura do descarte pela cultura do reaproveitamento, reutilização e reciclagem;

4. Estímulos à cultura de redução do consumo;

5. Imposição da internalização dos custos ambientais do consumo, conscientizando quanto ao desperdício e à degradação.

\section{REFERÊNCIAS BIBLIOGRÁFICAS}

BERNARDES, Maurício de Souza. Os desafios para efetivação da Política Nacional de Resíduos Sólidos frente a figura do consumidor-gerador. Revista Eletrônica do Curso de Direito da UFSM. v. 8, p. 196-207, 2013.

ELIAS, Norbert. A Sociedade dos indivíduos. SCHROTER, Michael (org.); RIBEIRO, Vera (trad.); Rio de Janeiro: Jorge Zahar, 1994.

FARIA, Guiomar Theresinha Estrella. Interpretação econômica do Direito. Porto Alegre: Livraria do Advogado, 1994.

FRANCISCO, Papa. Carta Encíclica Laudato Sí. Disponível em: <http://w2.vatican.va/content/francesco/pt/encyclicals/documents/papafrancesco.html>. Acessado em 22 set. 2015.

GHELLER, Giovanna. O tripé em que se apoia a sustentabilidade. Revista Espaço Aberto USP, ed 157, fev. 2014. Disponível em: <http://www.usp.br/espacoaberto/?materia=o-tripe-em-que-seapoia-a-sustentabilidade>. Acessado em 25 set. 2015.

GICO Jr., Ivo Teixeira. Metodologia e Epistemologia da Análise Econômica do Direito. Economic Analysis of Law Review, v. 1, p. 7-32, jan. /jun. 2010.

GONÇALVES, Oksandro Osdival; TOSI, Caroline Hammerschmidt Amaro. Teoria econômica do namoro e do matrimônio: uma ponderação sobre os custos e vantagens que determinam a decisão dos indivíduos. In: VI Congresso da Associação Brasileira de Direito e Economia - ABDE, 2013, Rio de Janeiro. Disponível em:< http://www.congresso.abde.com.br>. Acesso em 29 de jul. 2014. 
HEIDEGGER, Martin. Construir, habitar, pensar, trad. de Marcia Sá Cavalcante Schuback in: http://www.prourb.fau.ufrj.br/jkos/p2/heidegger_construir.pdf, p.1. Acesso em 20 de fevereiro de 2015.

KAHN, Suzana. Reflexões sobre sustentabilidade urbana. Cienc. Cult., São Paulo, v. 67, n. 1, março 2015. Disponível a partir de < http://cienciaecultura.bvs.br/scielo>. Acesso em 15 de abril de 2015.

KALIL, Ana Paula Maciel Costa; TAVARES NETO, José Querino. Elaboração de políticas públicas com base na governança: o caso da política nacional de resíduos sólidos. In: PAULA, Gil César Costa de; SILVA, José Antônio Tietzmann e; ARAÚJO, Luciane Martins de (cood.). Sustentabilidade: desafios e perspectivas. Goiás: Gráfica e Editora América. 2015.

KANASHIRO, Milena. Da antiga à nova Carta de Atenas - em busca de um paradigma espacial de sustentabilidade. Desenvolvimento e Meio ambiente, n. 9, p. 33-37, jan. /jun. Curitiba: Editora UFPR, 2004, p. 36-37.

LA NOUVELLE CHARTE d'ATHÈNES 2003, disponível em www.ceu-ectp.org. Acesso em 20/02/2015.

LEFEBVRE, Henri. O Direito à Cidade. Tradução de Rubens Frias. Primeira Edição, Editora Moraes, São Paulo. 1991, p. 10.

LUFT, Rosângela Marina. Políticas Públicas Urbanas: premissas e condições para a efetivação do direito à cidade. Belo Horizonte: Fórum, 2011.

MARRARA, Thiago. Bens Públicos: Domínio Urbano: Infra-estruturas. Belo Horizonte: Fórum, 2007, p. 248.

PANORAMA DOS RESÍDUOS SÓLIDOS NO BRASIL 2013 - Abrelpe. Disponível em: <http://www.abrelpe.org.br/Panorama/panorama2013.pdf>. Acessado em 23 set. 2015.

ROBBINS, Lionel. An Essay on the Nature and Significance of Economic Science. London: Macmillan, 1932, p. 15.Disponível em:<http://library.mises.org/books.pdf>. Acesso em 29 de jul. 2014

SILVA, José Afonso da. Direito Urbanístico Brasileiro. São Paulo: Malheiros, 2006.

WALDMAN, Maurício. Lixo: cenários e desafios - abordagens básicas para entender os resíduos sólidos. São Paulo: Cortez, 2010.

WEBER, M. La ciudad. Madri: La Piqueta, 1987.

Trabalho enviado em 25 de novembro de 2015.

Aceito em 04 de fevereiro de 2016. 